\title{
Retrofitting social housing in the UK: Home energy use and performance in a pre-Community Energy Saving Programme (CESP)
}

Heba Elsharkawy ${ }^{1}$, Peter Rutherford ${ }^{2}$

\begin{abstract}
Improving household energy efficiency is regarded as key to significantly curtailing domestic greenhouse gas emissions. Various policy instruments have been introduced to retrofit the existing domestic building stock in the UK; however, many fail to acknowledge the significant role that occupants' lifestyle play in energy use. The research discusses the results of a survey questionnaire administered to the residents of one of the pilot CESP schemes in Aspley, Nottingham. Factors affecting domestic energy consumption are explored, some of which relate to the building design, while others are under the direct control of the occupants. Significant findings related to home performance, home energy use, and tenants' lifestyle are investigated in the first phase of the research. The total number of responses to the survey represents $10 \%$ of around 900 properties eligible for the CESP scheme that have not been approached for the scheme uptake. It is evident from the survey results that the majority of the sample is aware of the basic energy-saving actions in everyday life but are not likely to take up the more difficult actions. In summary, retrofit programmes will reduce carbon emissions to some degree, whereas the bigger challenge is addressing habitual household energy consumption.
\end{abstract}

\section{Keywords}

\footnotetext{
${ }^{1}$ Welsh School of Architecture, Cardiff University, Bute Building, CF10 3NB Cardiff, UK

2 Department of Architecture and Built Environment, University of Nottingham, NG7 2RD, UK
} 
Home performance, Retrofit, Energy consumption, Community Energy Saving Programme (CESP), Lifestyle, Behaviour

\section{Introduction}

Energy use in the UK domestic sector accounts for a significant proportion of total national energy consumption. In 2012 domes-tic energy consumption accounted for nearly $29 \%$ of the total UK consumption of energy products [1]. Statistics, as may be expected, show that a significant proportion of household carbon emissions are due to space and water heating [2] and it is estimated that these activities account for around $83 \%$ of energy consumed in homes [1]. At present, it is estimated that the annual consumption of an average UK household is approximately $16,500 \mathrm{kWh}$ gas and $3300 \mathrm{kWh}$ electricity [3], which accounts for almost 5.5 tonnes of carbon dioxide emissions per household, per annum [4]. The UK Government has set a target for the reduction of carbon emissions by $80 \%$ by 2050 [1]. In order to meet the UK Government carbon emissions reduction targets, domestic emissions have to reduce by $17 \mathrm{MtCO} 2$ per annum by $2050[5]$.

Policies targeting newly built stock have failed to improve the UK's current domestic energy situation by meeting short-and medium-term environmental targets. Of those government initiatives: Warm Front, Smart meters programme, Carbon Emissions Reduction Target (CERT), Renewable Heat Incentive (RHI), Community Energy Saving Programme (CESP), amongst others. Thus, retrofitting existing domestic stock is considered a major priority to significantly reduce carbon emissions from the domestic sector; the current vision is to upgrade seven million homes by 2020 [6].

The CESP is designed to target income-deprived homes in defined areas through a house-by-house, street-by-street approach. The CESP is particularly focussed on barriers to the uptake of energy 
efficiency measures in low-income areas and 'hard-to-treat homes'. ${ }^{3}$ In the CESP target areas, there are barriers to implementing energy-efficiency measures for householders including lack of capital, lack of awareness, hidden costs and land-lord/tenant split incentives, among others. The scheme promotes a 'whole house' approach by installing a combination of measures that include internal wall insulation, loft insulation, replacing inefficient boilers, and fitting modern kitchens and bathrooms [7]. Those measures are delivered through partnerships between local authorities, energy companies, housing associations, and community groups. These partnerships have been designed to involve community-based organisations which are more engaged with their communities, alongside energy suppliers, thus facilitating the level of scheme uptake.

Despite considering policy initiatives a potential instrument for driving pro-environmental and sustainable behaviour [8-13]; the probability for policy and programmes to control energy consumption within households is relatively low when it comes to people's personal privacy and comfort concerning their own lifestyles and behaviour [14]. While there is evidence of a reduction in household carbon emissions in response to policy initiatives [15-18], this does not necessarily indicate that people are changing their way of life in order to lower their household energy consumption $[12,19]$. A significant implication to energy consumption behaviour is the 'rebound effect' [20] which may happen with energy efficiency improvements. With lowered energy consumption through, for example, energy efficiency measures, it has been mooted that cost savings (and as a result availability of more disposable income) could be diverted to other, equally environmentally damaging means such as purchasing more energy consuming appliances, increasing frequency of travel, purchasing of cars and so on [21]. Indeed, the UK Energy Research Centre predicts that the rebound effect could offset 10-30 per cent of energy savings [22].

\footnotetext{
${ }^{3} 1$ According to the BRE (2008) report, a 'Hard to Treat' dwelling is defined as "one that, for whatever reason, cannot accommodate 'staple' or cost-effective fabric energy efficiency measures. Four categories of dwellings have been considered HTT; dwellings with solid walls, dwellings off the gas network, dwellings with no loft and high-rise flats."
} 
Such implications have been discussed in previous studies, particularly those surrounding the feasibility of achieving the UK carbon reduction targets and the level of impact that policy might have on users' behaviour to support achieving these targets [23-25]. Other studies [26-28] found that lifestyles, habits, and social-demographic characteristics have a direct influence on pat-terns of domestic energy consumption. Some of these implications are explored in the present study. The article presents an overview of the data collected and analysed regarding home performance and energy consumption, and occupants' lifestyle and behaviour. It critically examines and reflects on some of the key findings from the survey, to explore how a sample of 'hard-to-treat' solid wall dwellings performed, and to assess trends of energy consumption of tenants of those dwellings.

\section{Research context and background}

Household energy consumption is influenced by various societal factors (both internal and external); these comprise technological developments, economic growth, demographic factors, institutional factors and cultural developments (known as TEDIC factors) [29 as cited in 19,30]. These five general macro-level factors (TEDIC) form the societal context that inevitably influences individual behaviour. Furthermore, there are interrelated forces that drive household energy consumption behaviour which have been explained in several studies $[10,11,19,31-33]$. It has been noted that energy use depends on multiple factors within households, including the family size, lifestyle, energy consumption behaviour, and appliance ownership $[10,11,19,31-33]$. Nonetheless, the choices of individuals are a key factor in the process of energy consumption. What people are willing to do in the interest of the environment depends critically on life-course experiences, current life-course phase and physical infrastructure of households [34]. Significant energy use differences may also be observed between income groups and among ethnic cultures $[11,35,36]$, besides attitudes, norms and beliefs which are very powerful energy consumption factors [8]. These are a few factors that dictate the demand for 
heating, cooling, and appliance use. However, it has been reported that full accounts of energy consumption determinants still do not exist [28].

It is inevitable that domestic energy-use determinants are inter-dependent and act within a range of combinations rather than additively according to each unique situation [33]. In order to encourage pro-social and pro-environmental individual behaviour, four key instruments were suggested by Gardner and Stern [36]: government laws, regulations and incentives; programmes of education, which attempt to encourage pro-social behaviour by giving people information and trying to change their attitudes; small social groups and communities, and the use of moral, religious, and/or ethical appeals. The first method, 'government law, regulations and incentives', is investigated in the present research as one of the potential instruments for driving sustainable energy consumption behaviour in the domestic sector.

In the UK, climate change policy planning has been closely related to energy policy. During the last decade, the UK has set a major priority to achieve low carbon emissions and to secure energy supplies driven by three core objectives; climate change, energy security and fuel poverty [37]. Given its contribution to energy consumption and carbon emissions, it is considered that the UK's domestic sector, consisting of both new and existing buildings, is a considerable domain where the Government's 2050 carbon reduction targets can be partly met.

The Building Regulations for new buildings set the target of zero carbon homes by 2016 and zero carbon buildings by 2019 [38]. The UK Government suggested a three-step policy approach to zero car-bon homes. These steps are: good fabric energy efficiency, on-site heat and power technologies, and allowable solutions for further carbon emissions reduction on site [39]. Thus, all new homes are required to have a mandatory Code for Sustainable Homes (CSH) indicating whether they had been assessed, and the performance of the home against the Code. The CSH extends on the Energy Performance Certificate (EPC), which has been mandatory since 2008 whenever a building has been built, sold or rented out. 
In order to help achieve this target through the existing domestic sector, the UK Government launched several initiatives and programmes in response to the diverse requirements of this sector. Primary among these is the Heat and Energy Saving Strategy (HESS), introduced in 2009 with a view to saving energy and decarbonising heating. The HESS incorporated several schemes such as the Car-bon Emissions Reduction Target (CERT), Feed in Tariffs (FiTs), and the Community Energy Saving Programme (CESP) among others [40]. The Aspley Super Warm Zone (ASWZ) has been chosen for the research as one of the 100 pilot CESP schemes in England, particularly in the East Midlands. It has also been specifically chosen for the investigation as, at the date of writing, no comparable research has been undertaken on ASWZ or any other CESP scheme in England.

\section{Research methodology}

\subsection{Research aim and design}

The study investigates the interrelationships between home energy efficiency and performance, and household energy consumption patterns. The aim is to understand the physical and socio-economic variables that affect home energy performance and energy consumption behaviour of a sample of households prior to the CESP energy upgrade, and gauge the findings against a sample of households post energy upgrade. The main objective is to make recommendations to support successful delivery of current and future policy schemes related to energy efficiency in the domestic sector.

The research adopts a 'before-and-after' design, which is a set of measurements taken from a group of respondents who are then subjected to an experimental variable before being measured again. In this case phase $\mathrm{A}$ is used as the control group whilst the experimental variable is the retrofit work done in respondents' households under the CESP scheme surveyed in phase B. The samples of respondents are not the same; however, they are matched samples in that they are both within the eligible area of the Aspley ward, are social housing properties, comprise similar-sized, solid-walled and 
energy-inefficient houses, and are all eligible for the scheme. The socio-demographic analysis undertaken in the second phase of the survey also ensured comparable samples of respondents in both phases. Phase A of the research sought to understand residents' attitudes and behaviour and explore how these related to home energy use and performance prior to the CESP upgrades in their dwellings. Phase B of the research sought to examine any detected changes in users' energy consumption behaviour and home energy performance and to realise the effect of the programme implementation on occupants' lifestyles and behaviour after their dwellings were upgraded. Phase A results and analysis are presented in this article, whereas phase B results will be presented elsewhere.

\subsection{Case study: ASWZ, Nottingham}

The field work survey was completed in the ASWZ; a recently implemented CESP scheme in Nottingham. The ASWZ scheme was funded by Scottish and Southern Electric and Nottingham City Council. Nottingham Energy Partnership (NEP) worked in partnership with private landlords and home owners in the area as a local charity in Nottingham. The scheme specifically targeted three lower super output areas ${ }^{4}$ (LSOAs) within the Aspley ward in Nottingham [41]. Those LSOAs comprise the sample domain of the survey undertaken for this study.

Regarding the physical characteristics of the properties surveyed, the dominant building style is vernacular to the 1930 s style and building regulations. The properties are built with solid brick walls characterised by similar thermal properties, external surface area, insulation and air-tightness. All houses are either semi-detached or terraced, with an average of three bedrooms each. The internal layout of the majority of properties in Aspley comprises the kitchen and the living room on the ground floor, and bedrooms and one bathroom on the first floor. According to Nottingham City Homes (NCH),

\footnotetext{
${ }^{4}$ LSOA - Lower Super Output Areas - are geographical areas of defined bound-aries, consistent sizes and similar social characteristics developed following the 2001 consensus to facilitate the calculation of Indices of Deprivation (Office for National Statistics).
} 
almost all houses have gas central heating $(\mathrm{GCH})$ as their main heating system but with varying heating efficiency owing to the technical features of the boilers. Table 1 summarises the characteristics of the dwellings.

\subsection{Questionnaire design}

The questionnaire was based on a scenario-building strategy aiming to map the personal constructs of a broad group of respondents. The aim was to undertake an analytical, relational survey which is less orientated towards representativeness and more towards finding associations and explanations, and less towards description and more towards prediction [42]. During the planning and design of the questionnaire, several studies performed in the UK concerning users' behaviour with respect to domestic energy consumption have been referred to $[15,17,43,44]$.

The questionnaire was prepared by the researcher and circulated between NEP and NCH representatives for feedback and suggestions on different aspects. The project team members were asked to advise on clarity of language used, question wording and order, and the flow between sections and questions. The researcher also wanted to ensure that all questions incorporated would provide useful information to each partner and would be as succinct as possible. The researcher had to assimilate all comments, and distil and refine questions accordingly before finalising the questionnaire; while ensuring all the previously mentioned pre-cautions had been considered and that the questions followed a logical and rational structure. Questionnaire A comprised five sections as shown in Table 2.

\subsection{The sample}

The targeted sample for phase A was households eligible for the ASWZ scheme that did not receive official information about the scheme. This was carefully considered when devising the sample from 
the $\mathrm{NCH}$ register of eligible properties for ASWZ where a stratified sampling approach was used. Stratified sampling ensures an equal opportunity of each unit being selected for the study in relation to their proportion within the total population [45], in this case ASWZ-eligible households within the CESP target area in Asp-ley (3 LSOAs). In partnership with NCH and NEP, 224 households, which constitute around $25 \%$ of the ASWZ-completed households, were selected and approached in a doorto-door survey approach. This approach ensured a reasonably high response rate, accurate sampling and minimum interviewer bias, while offering the bene-fit of a degree of direct contact. The total number of responses to the survey represented almost $10 \%$ of the total number of houses completed under the ASWZ scheme, at the time of writing.

\subsection{Data production}

The data collected were entered to SPSS and the coding included identifying valid responses to the closed, semi-closed and multiple response questions. Each coded response category was used as a variable in SPSS for subsequent statistical analysis. Variables were grouped under three categories in SPSS; nominal questions, ordinal questions, and Likert-scale questions. The collected data were analysed to produce descriptive and frequency statistics were undertaken to compare levels and rationale for tenants' energy consumption behaviour and home energy performance in the ASWZ. In order to address the specific aims of this study, the second and third sections of the questionnaire results along with significant correlations are hereby discussed; these are home energy use and performance, and tenants' lifestyle and behaviour.

\section{Results}

4.1. Home energy use and performance 
This section includes the analysis of questions concerning problems in respondents' homes, heating patterns, heating controls and trends in using them, and monthly utility bills. This part of the study forms an important basis to understanding tenants' perceptions of their homes which might help inform trends of heating their homes, some aspects of their lifestyle and behaviour, and predict their receptivity to the upcoming ASWZ scheme.

In response to physical problems in respondents' homes, the two problems experienced most were the draught and cold, with $36 \%$ and $20 \%$ respectively always experiencing it, followed by mould and condensation at 17\%; and finally problems with damp at $14 \%$ (see Fig. 1). Most respondents believed the cold and draught were due to the warped condition of the front and back doors, where $60 \%$ of the sample reported new front and back doors were crucial. This reflects people's awareness of the direct impact the doors may have on draught and cold levels.

With regards to questions concerning the main heating system in the household, $55 \%$ reported gas central heating $(\mathrm{GCH})$ as their primary heating system, $33 \%$ of households reported having both $\mathrm{GCH}$ and electric fire(s) as their two main heating systems, while 7\% reported electric fire(s) as the main heating system. The type of main heating systems reported in the questionnaire indicated considerable variation with the information provided by $\mathrm{NCH}$, which suggests that $91 \%$ of the social housing in Aspley has GCH as the main heating system.

The following aspect investigated was the energy used in the houses. Knowing the technical characteristics of the ASWZ dwellings (see Table 1), it was imperative to understand how residents heated their homes. Nearly $37 \%$ of households reported they heated most of the rooms most of the time while $20 \%$ heated all the rooms all the time. Households with these heating trends seemed to report less loft insulation being installed in their homes. This could either be due to not having any loft insulation done during their tenancy or due to their unawareness over the current situation of their loft insulation. Less loft insulation would imply greater heat loss through the building envelope. 
When exploring the results surrounding if, or how often, residents used the heating controls in their homes, only $33 \%$ of the sample reported they have all three heating controls; thermostatic radiator valves (TRVs), wall thermostat(s), and a boiler thermostat. Notably, $38 \%$ of households noted they have only one heating control, in most cases, the boiler thermostat. However, $\mathrm{NCH}$ asserts that the majority of dwellings in Aspley have all three heating controls fitted.

In response to respondents' priority for future home improvements, the order of priorities came as: first to a new bathroom followed by a new kitchen, while heating upgrading came as the third highest priority (see Fig. 2). This could possibly encourage people to sign up for the CESP intervention as it would provide those households with modern bathrooms and kitchens.

A key point of investigation for this study was the average monthly utility bills for gas and electricity in response to the dwellings being categorised as 'hard-to-treat'. Notably, the mean figures for monthly gas bills and monthly electricity bills have been found to be $£ 51$ and $£ 50$ respectively for the year 2011. This meant that, on average, a household in Aspley spends $f 100$ per month on utility bills, which comprises a significant proportion of the income compared with the average annual income reported as less than $£ 12,000$ for almost $70 \%$ of the sample. The following section delves more into tenants' lifestyles and behaviour trends in an attempt to relate these to their home energy use.

\subsection{Lifestyle and behaviour}

In several studies $[16,17,27]$, it was asserted that energy behaviour in households is undeniably associated with the general lifestyle. Thus, it was pertinent in this research to explore both; lifestyle trends of respondents and behaviour patterns related to energy use. As illustrated in Fig. 3, almost $52 \%$ of the sample always uses their computers and laptops on a daily basis, while $42 \%$ watch television for more than $3 \mathrm{~h}$ a day. This may be due to the high numbers of unemployed and 
economically inactive respondents (45\% in total) who might spend more time at home using their computers or watching the television, thus probably consuming energy through appliance use and heating their homes at a higher rate than house-holds with employed members. Another reason for the high rate of home appliance use might be that $60 \%$ of households include children and infants while $30 \%$ of households include members with a disability or ill-health who might also spend much of their time at home.

Thirty three per cent of the sample always goes for walks, $10 \%$ practice sports/exercise and $3 \%$ report that they always or some-times cycle. Besides going for walks in leisure time, another reason why one third of the sample goes for walks could be due to low car ownership rates, where only $29 \%$ of the sample owns a car. Thus, most people walk or use public transport for their work or errands. It has also emerged that one fifth of the sample always reads books, while $7 \%$ help at the local school, $7 \%$ volunteer in community work, and only $2 \%$ volunteer in environmental initiatives. Many people in this area might be environmentally aware, but could not afford to support environmental activities or buy environmentally friendly products [46].

In response to questions about energy awareness and behaviour (Fig. 4), $82 \%$ of the sample always recycles their home waste while only $30 \%$ compost. This may be due to the consistent information campaigns run via media sources about recycling as opposed to composting, and also due to the accessible and available recycling facilities and stations provided by Nottingham City Council across the city. The Department for Environment, Food, and Rural Affairs (DEFRA) [47] reported that recycling rates for households rose by approximately $40 \%$ in 2008 in England over the previous year's rate, which indicates that recycling has become more of a habit than a one-off action. Notably, the survey was undertaken before Notting-ham City Council introduced the bi-weekly bin collection initiative in 2011. The following top actions always taken by respondents are to turn off unwanted lights, boil only water needed in kettle, and use energy-saving lamps, with $78 \%, 60 \%$ and $57 \%$ respectively. Besides, $47 \%$ unplug unused equipment, while $45 \%$ wash clothes at lower temperatures. 
When analysing heating behaviour and heating trends, 32\% always heat occupied rooms only, which also has a moderate correlation with 'always using heating controls'. This relation shows that some people may understand how to use their heating controls and could be using them in an energyefficient way. However, it appears the majority require more knowledge and awareness with regards to how to use their heating controls. Thirty per cent always turn down their heating, whilst only $19 \%$ make more use of their programmers and $15 \%$ set their water thermostat lower. Another correlation appears between 'heat occupied rooms only' and 'make more use of the programmer' which might imply that people who always use their programmers do so effectively to heat occupied rooms only as opposed to those who never use them ( $13 \%$ of the sample).

With regards to the reasons for taking any of the previous actions; saving money was the main reason $73 \%$, followed by save energy, due to habit, and environmental concern, which represented minor results. The results appeared similar to those in a previous study [28] where saving money came as the main reason for respondents' willingness to change energy inefficient habits. This indicates that the first concern for most people is to save money, which proves that financial incentives (e.g. money, prizes, investment subsidies, reduction on income tax) could be effective in encouraging policy uptake and delivery besides the monetary savings from reduced energy bills [48-50].

When asked about whether they had ever received energy advice, $28 \%$ reported they received some advice from their suppliers through booklets and flyers, door-to-door sales, and via online energy trackers. On the other hand, the majority of respondents $72 \%$ mentioned they had never received advice concerning saving energy. However, it is not clear whether those who received advice actually acted on it; an issue which may require further research. Notably, in another study [28], it has been reported that $40 \%$ of respondents who received energy advice considered it useless. Thus, the subsequent question was concerned with whether they would like to receive energy advice. From open-ended questions in the survey, it appeared that many people had personal problems and concerns (e.g. illness/disability, unemployment, financial issues, among others) so they tended not to 
appreciate advice or suggestions on energy use. This could explain why more than half the respondents $53 \%$ would prefer not to receive any advice concerning energy savings, whilst $47 \%$ would. Of those who were interested in receiving advice, $65 \%$ preferred to receive it in written format such as leaflets and booklets, $25 \%$ preferred one-to-one sup-port in order to be provided with more comprehensive information, while the rest $10 \%$ preferred to receive information electronically. Interestingly, households who reported heating all the rooms all the time would like to receive advice on cutting energy use and bills.

\section{Discussion}

Phase A of the survey has been conducted, with data collected and analysed to provide substantial findings and correlations concerning home performance and energy consumption behaviour of a preCESP sample. The study shed light on aspects affecting home energy performance of a sample of residents in the ASWZ scheme geographic domain; dominant patterns of home energy use and some aspects of residents' lifestyle and energy consumption behaviour. It aimed to understand tenants' attitudes and behaviour in energy-inefficient homes and in so doing help develop suitable approaches to enhance the outcomes of retrofit programmes. It also explored appropriate means of communicating and disseminating energy advice and support based on participants' responses to the survey administered.

\subsection{Home energy use and performance}

Many tenants reported problems of cold and draught due to the warped front and back doors. In such a scheme which adopts a 'whole house' energy upgrade approach, it is a major downside that the key benefit of minimising heat loss from a heated house to the colder external environment by installing wall and loft insulation is reduced by heat loss through air infiltration via old and worn out doors. 
Another issue highlighted is the use of electric fires as a supplementary heating system. One of the main reasons for this may be that $\mathrm{GCH}$ could be quite costly to run in the long term due to continuous heat loss through the building envelope thus failure to reach comfort levels by GCH system alone [51]. As a result, electric fires might be used as a supplementary heating system, and also to boost heating. It was also noted that there appeared to be a considerable conflict between NCH reports on heating controls available to Aspley households and what tenants noted in their responses. This conflict may reflect a lack of awareness on the part of residents, both with respect to what is available within their homes and also of how controls are operated.

Another important aspect that emerged from the survey was that the mean, combined electricity and gas bills constitute more than $10 \%$ of the majority of the sample's income. This highlights the fact that many households could be experiencing fuel poverty where at least $10 \%$ of the annual income of those households is spent on fuel bills. Notably, the CESP scheme initially aimed to ensure that the annual savings in utility bills could be as high as $\mathrm{f300}$ GBP per household [52], which would have helped house-holds significantly in this area - if achieved. However, the annual rise in energy tariffs, tenants' inefficient use of heating controls, and patterns of energy consumption, challenge the full benefits of delivering the full potential of the scheme. It has also been reported that five out of six big energy suppliers have increased gas and electricity prices by between $6 \%$ and $11 \%$ in 2012 , thus further diminishing the scheme benefits [53].

\subsection{Lifestyle and behaviour}

It is evident from the survey results that the majority of the sample take on the most basic energysaving actions in everyday life; such as turning off unwanted lights, boiling only water needed in kettle, use energy-saving lamps, among others. This might also reflect people's concern about their fuel bills, which could be the key motivation for these actions. These findings may also indicate that the people 
who are relatively aware of a range of energy-saving actions might be receptive to other more significant ones (such as more efficient use of their heating systems), if they were provided with sufficient guidance.

However, residents are less likely to use the heating and hot water controls to reduce energy use, as those might be more complicated. As indicated above, factors that form the basis of choices, habits, and values of individuals often dictate an individual's decision to adopt environmentally sustainable behaviour, or not [8,32]. Personal carbon emissions from homes and transport account for almost half of the UK's carbon emissions. Thus, personal choices people make in their everyday lives such as turning off lights, and using heating controls more efficiently have the potential to significantly contribute to the UK's carbon emissions reduction targets [54].

In a study undertaken on UK social tenant users' behaviour [17] in energy-efficient homes where energy efficiency measures had been installed; only $23 \%$ of tenants surveyed were using their heating systems 'efficiently', as designed. The majority were using them to suit their lifestyle and gain reasonable value, but not utilising the systems at optimum efficiency. This study underlined the fact that what appeared best to the tenants, delivering them new efficient heating systems, may well not equate to optimum usage of the systems from an efficiency point of view, and may not in turn deliver 'design level' carbon savings [24]. The results from the present survey also indicate the crucial need to provide comprehensive energy advice and information to help people change their energyinefficient habits, despite the fact that probably only half the sample would be receptive to the advice.

From the survey results, it has been shown that ASWZ residents were not receiving adequate advice and information with respect to using their heating systems controls; therefore this is an area that requires further attention. Notably, NCH and NEP together refurbished a show home in the heart of the Aspley area, up to CESP standards before the scheme was initiated, for ASWZ tenants to visit this show home and use it as a temporary resort while the upgrade work on their homes was in progress. This show home has also been set up as a source of information and raising awareness in the 
community of what the ASWZ scheme comprises. However, NCH and NEP reported that the show home has not been utilised as efficiently as it was planned for, with only a low take-up by tenants. Thus, raising awareness and disseminating information regarding energy-saving actions is crucial for meeting carbon emissions reduction targets. Tailoring information required to reduce energy consumption according to the specific requirements and characteristics of target groups has proven worthwhile in other studies [55].

\section{Conclusion}

The study explored the factors affecting energy used for space heating, some of which relate to the building design - such as the specification of the building itself including its structure, materials composition, envelope, and some of which are under the direct control of the occupant - such as the lifestyle and patterns of energy use. The research also examined possible impacts of the CESP policy on energy consumption behaviour, together with an investigation of how implementing the policy could possibly lead to successful delivery. Hence, in order to assess whether CESP can effectively deliver on its aims, it was crucial to examine a number of key areas relating to home energy performance, and tenants' lifestyle and behaviour.

As energy consumption is habitual; to achieve successful behaviour change, old habits need to be broken and new ones established supported by policy programmes. It should be noted that unless there was continuous stimulation and follow-up, changes in behaviour would tend to be short-term $[28,56]$. Policy signals may have a major influence on social norms, ethical codes and cultural expectations. Policies send important signals to consumers about the kinds of behaviours that are rewarded in society, the kinds of attitudes that are valued, the goals and aspirations that are regarded as appropriate, what success means, and the worldview which consumers are expected to adhere to. Policy formulation and decision making with respect to environmental actions tend to be complicated by a number of factors; physical, psychological, socio-economic, ethical, political, and conflicting 
interests of different stakeholder groups. Indeed, the complexity of environ-mental decision problems is such that they may appear to defy rational analysis, and efforts to develop environmental policies often encounter controversy $[5,57]$. However, while policies may be in place to encourage environmentally sustainable behaviour, the choice of short-term reward that originates from existing habits may override paying the consequences for the action.

Another implication to effective policy delivery is the lack of transparency, where some policies such as the Carbon Emissions Reduction Target (CERT) and Renewables Obligations (RO) have been implemented in such a way that their benefits are not clear to the target audience [37]. This has been a main reason for the general unawareness of and disengagement of the public with the Government initiatives towards reducing carbon emissions. Consequently, a focus on the bottom-up approach in policy design, by actively engaging the public through more information dissemination and communication, could probably improve policy uptake and delivery.

Notably, single policy tools have not proven successful enough in reducing domestic energy consumption; the most effective interventions for household action often incorporate a combination of behavioural, economic and engineering elements. It is worth noting that Gardner and Stern's [12] four basic solutions for influencing consumption behaviour (mentioned previously) need to be carefully considered and integrated by policy and decision makers according to each target group and problem identified. Although the laws/regulations/incentives method may encourage individuals to behave in the public interest, the other three approaches encourage pro-environmental behaviour in other unique ways.

Consequently, effective interventions should incorporate several policy tools devised, according to the problem and target group, to change behaviour. These interventions also require the use of social marketing that targets community and social norms through mass media appeals and communitybased initiatives. Interventions need to address all sectors and parties within society (individuals, communities and businesses among others) to ensure they encapsulate diverse interests. Besides, 
economic initiatives for delivering carbon emission reduction need to shift towards driving behaviour change to ensure successful policy delivery as highlighted in the most recent Sustainable Development Strategy [58]. However, environmental policy should not only focus on the economic instruments; it also needs to incorporate educational tools that would help develop politically aware and more engaged individuals [59].

Research has shown that a combination of tailored information, goal setting and feedback resulted in significant reductions of gas and electricity use [55]. In that study, a combination of interventions encouraged households to adopt some energy-saving actions (such as lowering thermostat settings, turning off the heating when absent, washing at lower temperatures) and resulted in higher knowledge and awareness of energy conservation behaviour. In the current study, the majority of the sample preferred to have advice communicated through leaflets and booklets. Thus, to prove effective; simple, innovative, and informative brochures should be designed as appropriate to the specific needs of target groups.

Visual prompts are another means of driving sustainable energy consumption. Prompts prove effective in reminding people with repetitive behaviours that they may have the potential and ability to change their lifestyles to become more environmentally sustain-able. In fact, several studies have proven that prompts targeting specific behaviours have actually had a significant impact on promoting sustainable behaviour $[8,60,61]$. In a scheme such as the CESP, where houses are approached within the same neighbour-hood, activating the social norms among households by providing information and feedback, comparing between their energy performances, and awarding those who achieve the lowest levels of energy consumption could, in effect, improve the outcomes of such a scheme. It could also create a stronger link between the underlying concept of a 'community' scheme and the unique physical and social fabric of a community that may constitute a major strength for the scheme, if planned strategically. 
Hence, the options for encouraging behaviour change can be either through top-down initiatives; through policy instruments, economic benefits etc., or by bottom-up approaches; through education and information disseminated to individual households. Both approaches are required according to the target group and problem addressed, and both will entail benefits and drawbacks due to the complexity of energy consumption behaviour in the domestic sector. As the Aspley area in Nottingham is identified as one of the areas with multiple deprivations, delivering energy advice in the area would possibly encounter challenges owing to financial, social and cultural constraints. It is clearly recognised that with the variety of formats of information and advice that people reported they would prefer to receive, tailored information is indispensable. However, providing a household with information tends to result in higher knowledge levels, but not necessarily in behavioural changes or energy savings. Thus, consistent feedback and follow up should also be considered a crucial element of such a programme.

Ultimately, retrofitting homes will only reduce carbon emissions to a certain extent; whereas the bigger challenge of addressing behaviour patterns of consumption needs to be tack-led if existing homes were to meet the carbon emissions reduction target. Users' energy consumption behaviour and policy interventions will mean the difference between promising policy, and policy which in fact delivers on its aims for energy efficiency and car-bon emissions reduction. Further research needs to entail full and thorough examination of the barriers and opportunities hereby dis-cussed, to ensure a sustainable energy strategy for the UK housing sector.

\section{Acknowledgements}

The authors would like to acknowledge Nottingham City Homes ( $\mathrm{NCH})$ and Nottingham Energy Partnership (NEP) for their valuable help and assistance in facilitating this research project. 


\section{References}

[1] DECC, Energy Consumption in the United Kingdom, Department of Energy and Climate Change, London, 2013.

[2] GCH, Gloucester City Homes Environmental Strategy 2010-2013, Gloucester City Homes, Gloucester, 2010.

[3] Ofgem, The Final Report of the Community Energy Saving Programme (CESP) 2009-2012, Ofgem, London, 2013.

[4] EST, Save Energy, Money and the Environment, E\&OC Energy Saving Trust, London, 2009.

[5] A. McManus, M.R. Gaterell, L.E. Coates, The potential of the Code for Sustainable Homes to deliver genuine 'sustainable energy' in the UK social housing sector, Energy Policy 38 (4) (2010) 20132019.

[6] DECC, Warm Homes, Greener Homes: A strategy for Household Energy Management, Department of Energy and Climate Change, London, 2010.

[7] P. Richards, D. Hough, Energy Efficiency Schemes, House of the Commons Library, London, 2012.

[8] D. McKenzie-Mohr, Fostering Sustainable Behavior: An Introduction to Community-Based Social Marketing, 3rd ed., New Society Publishers, Gabriola Island, 2011.

[9] Y. Parag, S. Darby, Consumer-supplier-government triangular relations: rethinking the UK policy path for carbon emissions reduction from the UK residential sector, Energy Policy 37 (10) (2009) 3984-3992. 
[10] P. Stern, Changing behavior in households and communities: what have we learned? in: T. Dietz, P. Stern (Eds.), New Tools for Environmental Protection: Education, Information, and Voluntary Measures, National Academy Press, Washington, 2002, pp. 201-211.

[11] L. Lutzenhiser, Social structure, culture and technology: modelling the driving forces of household energy consumption, in: P. Stern, et al. (Eds.), Environmentally Significant Consumption: Research Directions, National Academy Press, Washington, 1997, pp. 77-91.

[12] G.T. Gardner, P.C. Stern, Environmental Problems and Human Behaviour, Allyn and Bacon, MA, 1996.

[13] P. Stern, L. Berry, E. Hirst, Residential conservation incentives Energy Policy 13 (2) (1985) 133142.

[14] P. Soderholm, Environmental policy and household behaviour: an introduction to the volume, in: P. Soderholm (Ed.), Environmental Policy and Household Behaviour: Sustainability and Everyday Life, Earthscan, London, 2010, pp. 1-9.

[15] J.L. Patterson, Arbed 1 Scheme: Evaluation of the Warm Wales Programme. Project Report, Welsh School of Architecture, Cardiff University, Cardiff, 2012.

[16] B. Gatersleben, 21st Century Living Project: Analyses of Second Value Survey and Comparative Analyses Examining Change, RESOLVE, University of Surrey, Surrey, 2011.

[17] J. Pett, P. Guertler, User Behaviour in Energy Efficient Homes, Association for the Conservation of Energy, London, 2004.

[18] Alembic Research, Revisiting Easthall: 10 years on, Energy Action Scotland \& Office for Standards in Education (OFSTED), Glasgow, 2002. 
[19] W. Abrahamse, Energy Conservation Through Behavioral Change: Examining the Effectiveness of a Tailor-made Approach (PhD thesis), Grafisch Bedrijf Pon-sen en Looijen bv, Wageningen, Reitsum, Netherlands, 2007.

[20] H. Saunders, A view from the macro-side: rebound, backfire, and Khazzoom-Brookes, Energy Policy 28 (2000) 439-449.

[21] S. Sorrell, H. Herring, Introduction, in: H. Herring, S. Sorrell (Eds.), Energy Efficiency and Sustainable Consumption: The Rebound Effect, Palgrave McMillan, London, 2009, pp. 1-21.

[22] W. Swan, M. Wetherill, C. Abbott, SCRI Research Report 5: A Review of the UK Domestic Energy System, SCRI, Salford, 2010.

[23] O. Guerra-Santin, C. Tweed, H. Jenkins, S. Jiang, Monitoring the performance of low energy dwellings: two UK case studies, Energy and Buildings 64 (2013) 32-40.

[24] H. Elsharkawy, P. Rutherford, R. Wilson, The Code for Sustainable Homes as a viable driver towards a zero carbon future in UK, in: M. Bodart, A. Evrard (Eds.), PLEA 2011 - 27th International Conference on Passive and Low Energy Architecture, vol. 1, Presses Universitaires, Louvain-la-Neuve, 2011, pp. 313-318.

[25] M. Osmani, A. O'Reilly, Feasibility of zero carbon homes in England by 2016: a house builder's perspective, Building and Environment 44 (9) (2009) 1917-1924.

[26] O. Guerra-Santin, Behavioural patterns and user profiles related to energy consumption for heating, Energy and Buildings 43 (10) (2011) 2662-2672.

[27] W.F. Van Raaj, T.M.M. Verhallen, Patterns of residential energy behaviour, Journal of Economic Psychology 4 (1-2) (1983) 85-106.

[28] G.M. Huebner, J. Cooper, K. Jones, Domestic energy consumption: what role do comfort, habit, and knowledge about the heating system play? Energy and Buildings 66 (2013) 626-636. 
[29] J.B. Opschoor, After us the Deluge: Conditions for a Sustainable Use of the Environment, Kok Agora Publisher, Kampen, Overijssel, 1989 (in Dutch).

[30] B. Gatersleben, C. Vlek, Household consumption, quality of life and environmental impacts: a psychological perspective and empirical study, in: K. Noorman, T. Uiterkamp (Eds.), Green Households? Doestic Consumers Environment and Sustainability, Earthscan, London, 1998, pp. 141179.

[31] Y.G. Yohanis, Domestic energy use and householders' energy behaviour, Energy Policy 41 (2012) 654-665.

[32] W. Abrahamse, L. Steg, C. Vlek, T. Rothengatter, A review of intervention studies aimed at household energy conservation, Journal of Environmental Psychology 25 (3) (2005) 273-291.

[33] P.C. Stern, T. Dietz, V.W. Ruttan, R.H. Socolow, J.L. Sweeney, Consumption as a problem for environmental science, in: P.C. Stern, et al. (Eds.), Environmentally Significant Consumption: Research Directions, National Academy Press, Washington, 1997, pp. 1-11.

[34] M. Martensson, R. Pattersson, Everyday life contexts and the environment, in: A. Biel, B. Hansson, M. Martensson (Eds.), Individual and Structural Determinants of Environmental Practice, Ashgate Publisher Limited, Aldershot, 2003, pp. 26-60.

[35] L. Lutzenhiser, B. Hackett, Social stratification and environmental degradation understanding household CO2 production, Social Problems 40 (1) (1993) 50-73.

[36] G.T. Gardner, P.C. Stern, Environmental Problems and Human Behaviour, 2nd ed., Pearson Custom Publishing, Boston, 2002.

[37] P. Ekins, J. Skea, M. Winskel, UK energy policy and institutions, in: J. Skea, P. Ekins, M. Winskel (Eds.), Energy 2050: Making the Transition to a Secure, Low Carbon Energy System, Earthscan, London, 2011, pp. 41-66. 
[38] N. Eyre, J. Anable, C. Brand, R. Layberry, N. Strachan, The way we live fom now on: lifestyle and energy consumption, in: J. Skea, P. Ekins, M. Winskel (Eds.), Energy 2050: Making the Transition to a Secure Low Carbon Energy System, Earthscan, London, 2011, pp. 258-294.

[39] ZeroCarbonHub, Zero Carbon Strategies for tomorrow's new homes, Zero Carbon Hub \& NHBC Foundation, London, 2003.

[40] G. Anandarajah, P. Ekins, N. Strachan, Pathways to a low carbon economy, in: J. Skea, P.W.M. Ekins, J. Skea (Eds.), Energy 2050: Making the Transition to a Secure, Low Carbon Energy System, Earthscan, London, 2011, pp. 105-145.

[41] Nottingham City Council, Ward Data (Online), Nottingham City Council, 2011, Available at: http://www.nottinghamcity.gov.uk/index.aspx?articleid=2320 (accessed 22.02.12).

[42] A.N. Oppenheim, Questionnaire Design, Interviewing and Attitude Measurement, Continuum International Publishing Group Ltd, London, 1992.

[43] B. Gatersleben, E. White, W. Abrahamse, T. Jackson, D. Uzzell, Values and sustainable lifestyles, Architectural Science Review 53 (2010) 1-14.

[44] OFSTED, Revisiting Easthall 10 years on, Office for Standards in Education, London, 2002.

[45] M. Denscombe, The Good Research Guide: For Small-scale Social Research Projects, 3rd ed., Open University Press, New York, 2007.

[46] Nomad Plus, Aspley Ward Customer Profile, Experian Limited GIS Team and Policy \& Information Team, Nottingham City Council, Nottingham, 2006.

[47] DEFRA., A Framework for Pro-environmental Behaviour, Department for Environment, Food and Rural Affairs (Defra), London, 2008.

[48] K. Mizobuchi, K. Takeuchi, The influences of financial and non-financial factors on energysaving behaviour: a field experiment in Japan, Energy Policy 63 (2013) 775-787. 
[49] P. Bertoldi, S. Rezessy, V. Oikonomou, Rewarding energy savings rather than energy efficiency: exploring the concept of a feed-in tariff for energy savings, Energy Policy 56 (2013) 526-535.

[50] C. Hoicka, P. Parker, J. Andrey, Residential energy efficiency retrofits: how program design affects participation and outcomes, Energy Policy 65 (2014) 594-607.

[51] O. Guerra Santin, L. Itard, H. Visscher, The effect of occupancy and building characteristics on energy use for space and water heating in Dutch residential stock, Energy and Buildings 41 (11) (2009) $1223-1232$.

[52] DECC, Impact Assessment of proposals for implementation of the Community Energy Saving Programme (CESP), Crown copyright Department of Energy and Climate Change (DECC), London, 2009.

[53] P. Bolton, Energy Prices, House of the Commons Library, London, 2013.

[54] N. Eyre, B. Flanagan, K. Double, Engaging people in saving energy on a large scale: lessons from programmes of the energy saving trust in the UK, in: L. Whit-marsh, S.L.I. O'Neill (Eds.), Engaging the Public with Climate Change: Behaviour Change and Communication, Earthscan, London, 2011, pp. $141-160$.

[55] W. Abrahamse, L. Steg, C. Vlek, T. Rothengatter, The effect of tailored information, goal setting, and tailored feedback on household energy use, energy-related behaviors, and behavioral antecedents, Journal of Environmental Psychology 27 (4) (2007) 265-276.

[56] O.A. Nisiforou, S. Poullis, A.G. Charalambides, Behaviour, attitudes and opinion of large enterprise employees with regard to their energy usage habits and adoption of energy saving measures, Energy and Buildings 55 (2012) 299-311.

[57] R.S. Nickerson, Psychology and Environmental Change, Lawrence Erlbaum Associates, Inc., Mahwah, 2003. 
[58] DEFRA, Securing the Future: UK Government Sustainable Development Strategy, The Stationary Office \& The Department of the Environment, Food and Rural Affairs, London, 2005.

[59] P. Soderholm, Addressing environmental concern at the household level: concluding remarks, in: P. Soderholm (Ed.), Environmental Policy and Household Behaviour: Sustainability and Everyday Life, Earthscan, London, 2010, pp. 239-249.

[60] R.B. Cialdini, Influencing change: applying behavioral science research insights to reframe environmental policy and program, in: Behavior, Energy and Climate Change 2010, Sacramento, 2010.

[61] T. Kurz, N. Donaghue, I. Walker, Utilizing a social-ecological framework to pro-mote water and energy conservation: a field experiment, Journal of Applied Social Psychology 35 (6) (2005) 12811300. 
Fig.1. Problems experienced in the home

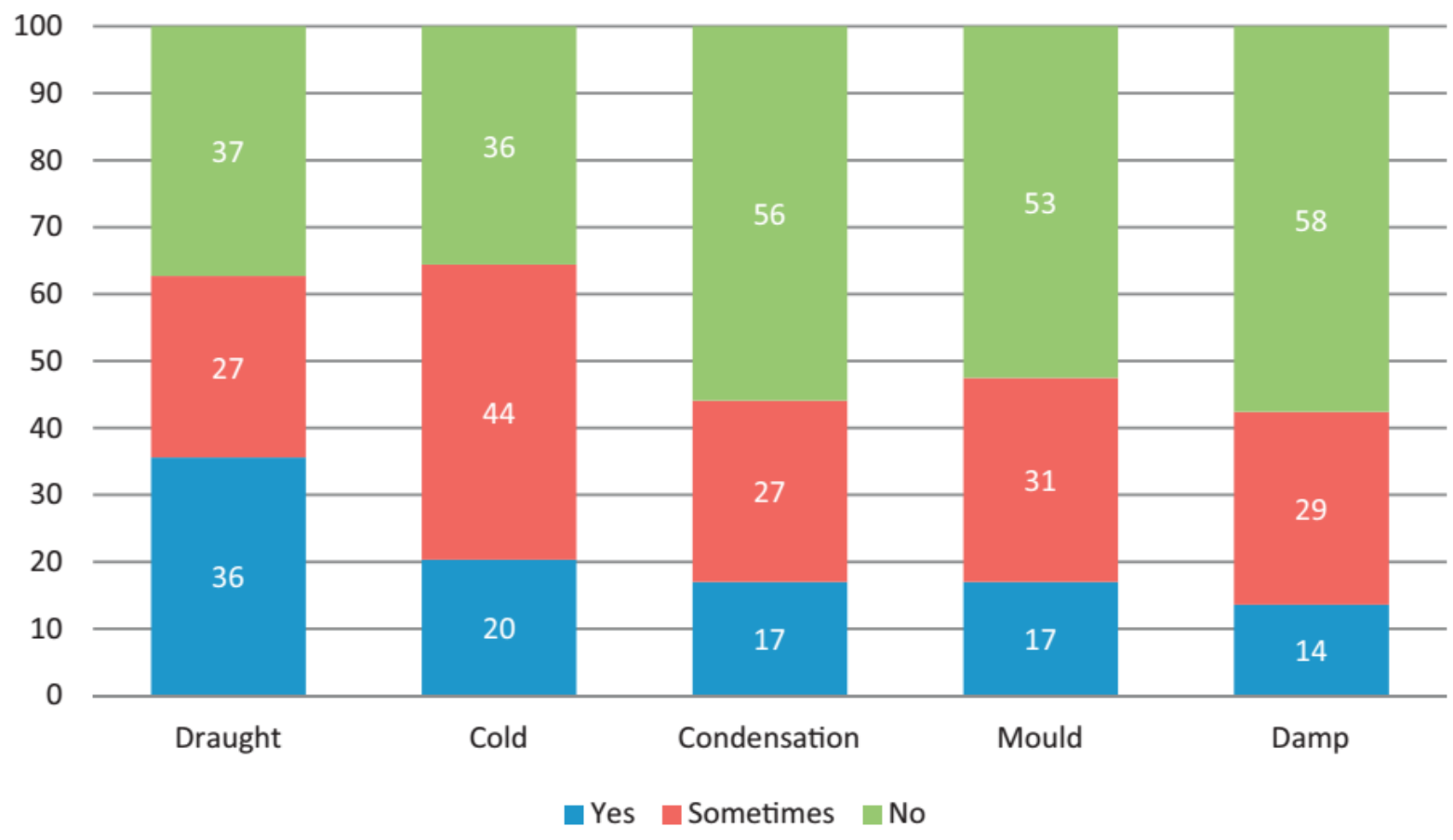

Fig. 2. Priorities for home improvement

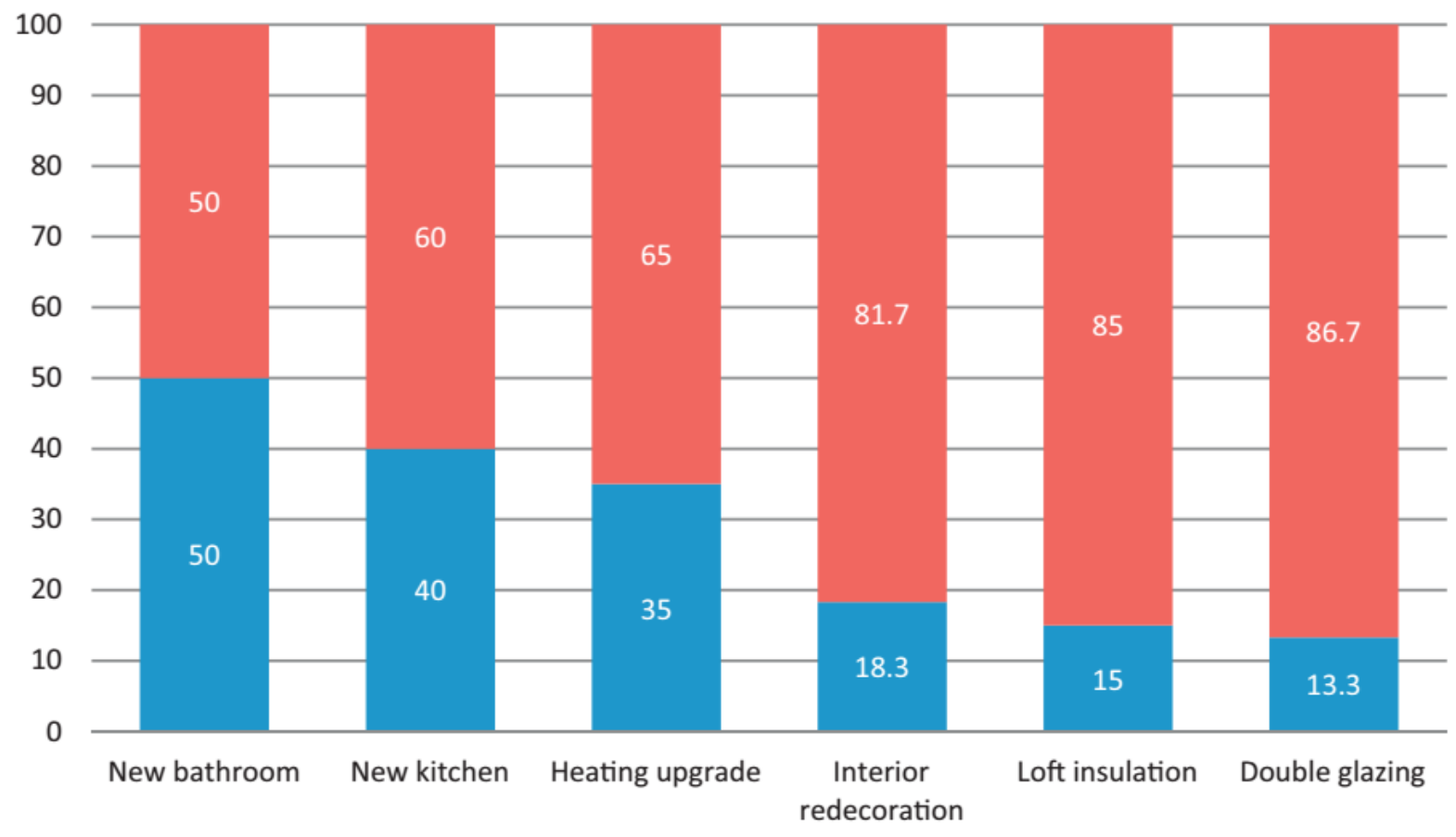

- yes no

Fig. 3. Lifestyle patterns 


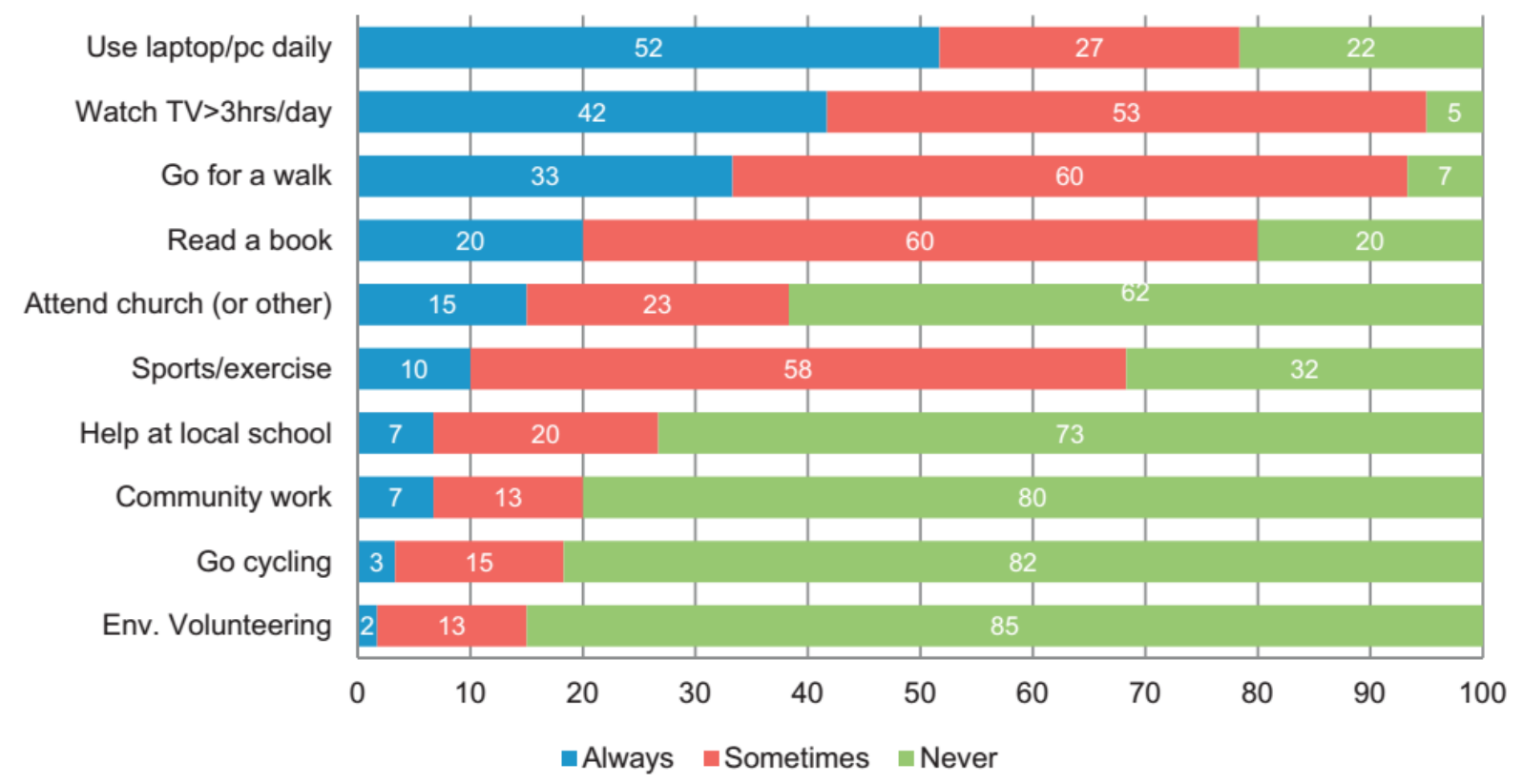


Table 1. Characteristics of dwellings in the ASWZ, Nottingham

\begin{tabular}{|l|l|}
\hline Type of dwellings & Semi-detached / terraced \\
\hline Type and date of construction & Solid brick wall (9" thickness), 1930s \\
\hline Number of occupants (mean) & Three occupants / dwelling \\
\hline Layout & $\begin{array}{l}\text { Ground floor: living room, kitchen } \\
\text { First floor: } 2 / 3 \text { bedrooms, bathroom }\end{array}$ \\
\hline Windows & $\begin{array}{l}\text { The majority (91\%) have double glazed } \\
\text { windows. The rest have a mix of single and } \\
\text { double glazing }\end{array}$ \\
\hline Main heating system & Gas central heating (GCH) \\
\hline
\end{tabular}

Table 2. Questionnaire A sections and questions.

\begin{tabular}{|c|c|}
\hline $\begin{array}{l}\text { Section } 1 \\
\text { General household information }\end{array}$ & $\begin{array}{l}\text { - Number and type of rooms } \\
\text { - Main and secondary heating systems } \\
\text { - Type of glazing and doors } \\
\text { - General improvements made to date } \\
\text { - Priorities for future improvements }\end{array}$ \\
\hline $\begin{array}{l}\text { Section } 2 \\
\text { Home energy use and performance }\end{array}$ & $\begin{array}{l}\text { - Heating trends, heating controls available and } \\
\text { frequency of use } \\
\text { - Problems experienced (draught, cold, etc.) } \\
\text { - Number and type of electric appliances owned } \\
\text { - Average monthly utility bills paid } \\
\text { - Whether they received energy advice }\end{array}$ \\
\hline $\begin{array}{l}\text { Section } 3 \\
\text { Lifestyle and behaviour }\end{array}$ & $\begin{array}{l}\text { - Lifestyle pattern } \\
\text { - Environmental actions }\end{array}$ \\
\hline $\begin{array}{l}\text { Section } 4 \\
\text { Respondents' awareness of the ASWZ }\end{array}$ & $\begin{array}{l}\text { - Expectations from ASWZ } \\
\text { - If respondents would consider signing up for it } \\
\text { - If respondents would be ready to contribute } \\
\text { towards their home retrofit costs }\end{array}$ \\
\hline $\begin{array}{l}\text { Section } 5 \\
\text { Socio-demographic information }\end{array}$ & $\begin{array}{l}\text { - Demographics of the household } \\
\text { - Employment activity } \\
\text { - Income } \\
\text { - Car ownership } \\
\text { - Health status }\end{array}$ \\
\hline
\end{tabular}

